\title{
Cenlestato
}

\section{A altmetria na prática e o papel dos bibliotecários no seu uso e aplicação}

\author{
Ronaldo Ferreira Araujo \\ Doutor; Universidade Federal de Alagoas, Maceió, AL, Brasil \\ ronaldfa@gmail.com
}

NASCIMENTO, Andrea Gonçalves do. Altmetria para bibliotecários: guia prático de métricas alternativas para avaliação da produção científica. Rio de Janeiro: Revolução eBook, 2016.

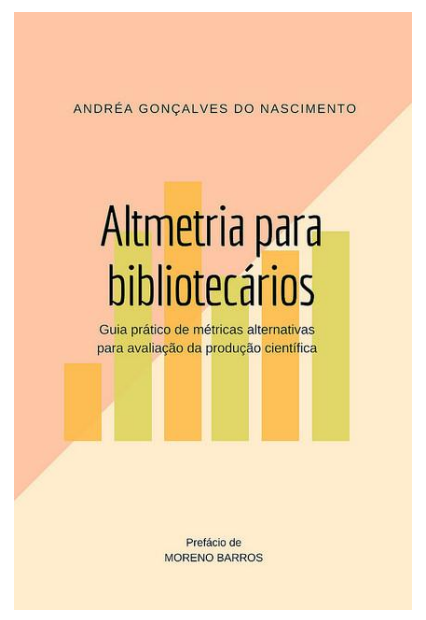

Resumo: Resenha do livro Altmetria para bibliotecários: guia prático de métricas alternativas para avaliação da produção científica de Andrea Gonçalves do Nascimento. A obra apresenta os conceitos básicos e principais aplicações das métricas alternativas, elucidando questões gerais e específicas a sua compreensão tendo como foco principal seu uso prático pelos profissionais bibliotecários.

Palavras-chave: Altmetria. Atenção online. Bibliotecários.

O campo dos estudos métricos da informação se dedica à análise e compreensão dos aspectos quantitativos da produção, disseminação e utilização da informação, independentemente de seu formato ou origem. Tais estudos têm desempenhado um papel importante na avaliação da produção científica e tecnológica. O uso intensivo das tecnologias web e suas implicações na comunicação científica com atividades de pesquisa cada vez mais baseadas em 
recursos da internet e em rede têm gerado novos indicadores, que por sua vez, têm sido agrupados no emergente campo das métricas alternativas ou altmetria.

Escrito de forma cuidadosa e atenta à responsabilidade que é abordar novas disciplinas ou campos de estudos, como é o caso da altmetria, o livro Altmetria para bibliotecários: guia prático de métricas alternativas para avaliação da produção científica, de Andrea Gonçalves do Nascimento, apresenta os conceitos básicos e principais aplicações das métricas alternativas elucidando questões gerais e específicas a sua compreensão, como o que são, para que servem e como utilizá-las tendo, como foco principal, seu uso prático pelos profissionais bibliotecários.

O livro tem uma abordagem prática sobre o tema, é escrito didaticamente como um guia e atende também a pesquisadores, editores científicos e outros profissionais que se interessam pela avaliação da produção científica e desejam manter-se atualizados em relação às mudanças recentes e futuras ligadas às métricas alternativas. Tem por objetivo traçar um panorama inicial sobre o significado do impacto na avaliação da produção científica, apresentar as formas de avaliação tradicionais baseadas na bibliometria, contextualizar o surgimento das métricas alternativas e introduzir informações essenciais sobre o seu uso e aplicação, sobretudo considerando os desafios e particularidades da adoção da altmetria no Brasil.

O guia é dividido em três partes: "Avaliação da produção científica", "Ferramentas para métricas alternativas" e "Altmetria na prática". Ao final, ainda apresenta um glossário. Na parte introdutória, com um tom de reconhecimento e responsabilização da atuação profissional, Nascimento (2016) ressalta o papel dos bibliotecários em auxiliar seu público a se preparar para a próxima geração de métricas de impacto da pesquisa, ressaltando, para isso, a importância de terem conhecimento sobre a literatura e o estado atual de discussão sobre a área, conhecer e explorar as ferramentas para coleta e geração de métricas alternativas e encontrar formas de integrar a altmetria às práticas de divulgação e treinamento da biblioteca. 
Na primeira parte, a autora discorre sobre a avaliação da produção científica, os níveis de medição de impacto acadêmico: do artigo (Article-Level Metrics ou Métricas de artigo), do periódico (Fator de Impacto, Índice de imediatez, Programa Qualis, Indexação em bases de dados nacionais e internacionais), do autor (Índice h, Índice i10) e da instituição (rankings institucionais baseados em citações ou de atenção online) - e as duas principais formas de mensuração: a tradicional, baseada em indicadores bibliométricos, e as métricas alternativas, compreendidas em indicadores de visibilidade, alcance e uso com base em recursos da web social. Para essa discussão, o impacto científico ganha certa centralidade e carrega uma conotação de influência, de alcance e valor alimentando o sistema de recompensa científica que decorre do pressuposto de que a pesquisa mais valiosa recebe, por exemplo, mais citações. Ao abordá-lo, a autora discorre sobre seu significado, cálculo, índices, indicadores e críticas a sua prática na comunicação científica.

Diante das críticas apresentadas e das implicações das mudanças dos avanços tecnológicos na comunicação científica, a autora reforça a necessidade de incorporação de novas técnicas, novos métodos, novos dados, novas métricas que representem todo o espectro de interações em torno da produção científica e de seus atores para medir e avaliar o impacto acadêmico. Com a adoção de métricas alternativas, a medição de impacto resulta em um conjunto de fatores que vai muito além da quantidade de citações recebidas, mas inclui também medidas de quanto um trabalho foi visto, baixado e compartilhado na web, e o que se está dizendo sobre esse artigo tanto na revisão por pares, como em comentários do público especializado e em geral.

$\mathrm{Na}$ segunda parte do livro, Nascimento (2016) discorre sobre as principais ferramentas de altmetria disponíveis no mercado para avaliação e classificação de artigos, periódicos, autores e instituições, a saber: a Altmetric, empresa de atuação mais diversificada, com funcionalidades e soluções desenhadas para bibliotecários, editores e pesquisadores; a ImpactStory, com foco na análise individual de pesquisadores; a PLOS ALM, que atende principalmente às demandas de editores científicos; e a Plum Analytics, que se 
dedica ao desenvolvimento de ferramentas para o mercado institucional acadêmico. As ferramentas são descritas por meio de um breve histórico, com informações sobre seus fundadores, sua data de criação, funcionalidades, limitações, padrões que exigem, fontes de dados que consideram e indicadores que geram, tendo em vista as particularidades do segmento acadêmico do público que atendem.

A terceira e última parte do livro tem o objetivo de induzir e apoiar uma experiência mais prática do uso das métricas alternativas por bibliotecários para atender a contextos específicos - na gestão da biblioteca, no apoio aos pesquisadores e editores científicos, e na avaliação institucional - e inclui exemplos de implementação e sugestões de exercícios práticos de reconhecimento e engajamento para quem deseja começar a utilizar as ferramentas de altmetria, além de outras sugestões e dicas para aqueles que desejarem manter-se atualizados e continuar participando de discussões sobre o assunto.

$\mathrm{Na}$ gestão da biblioteca, a altmetria pode trazer uma perspectiva adicional para tomar decisões na gestão de coleções, sendo possível, por exemplo, identificar potenciais novos títulos para o acervo, ver uma lista dos periódicos mais populares que publicaram artigos sobre um determinado tema, identificar artigos de interesse do seu público pelo critério de número de visitas e downloads por assunto ou área do conhecimento. No apoio a pesquisadores, orientar para os diversos sites onde um pesquisador pode se cadastrar para promover seus trabalhos, socializar com seus pares e comunidade, trocar conhecimentos e referências. A altmetria pode ainda ajudar a revelar novas dimensões de uso e influência, apontar tendências a serem examinadas pelos editores, e angariar novos autores atraídos por indicadores positivos.

Durante o desenvolvimento da obra percebe-se uma boa construção da relação de complementariedade entre a altmetria e os estudos bibliométricos e de citação, um dos argumentos é que, basicamente, em qualquer atividade na qual se utilizam métricas tradicionais de avaliação acadêmica, existe a oportunidade de enriquecer os resultados obtidos com métricas alternativas e 
ainda criar possibilidades inovadoras de avaliação. Segundo Nascimento (2016), para que as métricas alternativas passem a ser utilizadas por bibliotecários na prática, é essencial aos profissionais conhecer e explorar diferentes categorias de métricas e ferramentas, entender suas características e o tipo de uso mais adequado para cada situação e público.

A abordagem de Nascimento (2016) é pertinente neste momento em que a avaliação científica tem sido pautada por movimentos e práticas da ciência aberta nas quais tecnologias digitais e recursos da web social ampliam consideravelmente a atenção online e o impacto social das publicações e dos resultados de pesquisa, tornando a atividade científica mais interativa e colaborativa e possibilitando a medição da visibilidade e engajamento dentro e fora da academia. No entanto, talvez falte à obra a problematização e abordagem crítica quanto à formação do profissional, sobretudo as deficiências desta e a necessidade de inclusão de conteúdos voltados aos estudos métricos de avaliação de ciência e tecnologia que nas grades curriculares dos cursos de Biblioteconomia ofertados no Brasil ainda são baixos (OLIVEIRA, 2011). Dada a importância dos estudos métricos da informação para a comunicação científica e a inquestionável proximidade dos bibliotecários para atuarem nesse nicho, as instituições precisam ampliar a oferta de conteúdos formativos sobre a temática na graduação e o profissional que deseja atuar nesse campo deve buscar uma complementariedade dessa formação participando de eventos, realizando cursos e investindo em sua educação continuada.

O emergente campo das métricas alternativas conta com poucas publicações no cenário nacional - sobretudo de obras que se dedicam integralmente ao assunto como a obra aqui analisada. Atualmente, há registro de apenas duas coletâneas que abordam parcialmente o campo: (1) o livro Fronteiras da Ciência da Informação, organizado por Albagli (2013), conta com um capítulo que aborda estudos da webometria e da altmetria (GOUVEIA; LANG, 2013) e outro sobre comunicação científica e redes sociais (PRÍNCIPE, 2013); e (2) o livro Estudos métricos da informação na web, organizado por Araújo (2015a), conta com um capítulo que situa a altmetria no campo dos 
estudos cibermétricos da comunicação científica (ARAÚJO, 2015b) e outro que aborda as métricas da comunicação científica na web social apresentando um breve histórico sobre altmetria (SOUZA, 2015).

Nesse cenário, por ser o primeiro livro totalmente voltado ao tema da altmetria, Nascimento (2016) além de contribuir com a elucidação de seus aspectos gerais e específicos, o faz por meio do seu diálogo estreito com a atuação profissional do bibliotecário. A importância da experimentação prática é evidente na obra e a autora reforça que após conhecer as ferramentas e suas possibilidades, fazer exercícios práticos utilizando essas ferramentas é outro passo importante. Ainda nessa evidência a obra assume que a prática ainda é a melhor amiga da perfeição, e praticar o uso de métricas alternativas é o melhor que se pode fazer para conhecê-las bem.

\section{Referências}

ALBAGLI, S. (Org.). Fronteiras da ciência da informação. Brasília: IBICT, 2013.

ARAUJO, R. F. (Org.). Estudos métricos da informação na web: atores, ações e dispositivos informacionais. Maceió: Edufal, 2015a.

ARAUJO, R. F. Os estudos cibermétricos da informação: das estruturas web aos recursos da web social. In: ARAUJO, R. F. (Org.). Estudos métricos da informação na web: atores, ações e dispositivos informacionais. Maceió: Edufal, 2015b. p. 17-36.

GOUVEIA, F. C.; LANG, P. Da webometria à altmetria: uma jornada por uma ciência emergente. In: ALBAGLI, S (Org.). Fronteiras da ciência da informação. Brasília: IBICT, 2013. p. 172-195.

NASCIMENTO, A. G. do. Altmetria para bibliotecários: guia prático de métricas alternativas para avaliação da produção científica. Rio de Janeiro: Revolução eBook, 2016.

OLIVEIRA, D. A. A influência da ciência da informação nos cursos de graduação em biblioteconomia no Brasil: formação docente, aspectos teóricos e manifestações temáticas. 2011. 184 f. Tese (Doutorado em Ciência da Informação)-Escola de Ciência da Informação, Universidade Federal de Minas Gerais, Belo Horizonte, 2011. 
PRÍNCIPE, Eloisa. Comunicação científica e redes sociais. In: ALBAGLI, S (Org.). Fronteiras da ciência da informação. Brasília: IBICT, 2013. p. 196216.

SOUZA, I. V. P. Métricas da comunicação científica na web social: breve histórico da altmetria. In: ARAUJO, R. F. (Org.). Estudos métricos da informação na web: atores, ações e dispositivos informacionais. Maceió: Edufal, 2015. p. 37-54.

\title{
Bibliometrics in practice and the role of librarians in their use and application
}

\begin{abstract}
This book critical review talks about Andrea Gonçalves do Nascimento's Altmetrics for librarians: practical guide to alternative metrics for evaluation of the scientific production. The work presents the basic concepts and main applications of the alternative metrics elucidating general and specific questions to their understanding having as main focus their practical use by the professional librarians.
\end{abstract}

Keywords: Altmetrics. Online attention. Librarians.

Recebido: $18 / 03 / 2017$

Aceito: $13 / 05 / 2017$ 